general, the health services (ambulance and hospital) have little or no equipment or training to deal with such casualties. If a Tokyo type incident occurred in the United Kingdom with a more efficient dispersal of sarin, the potential for morbidity and mortality among health care providers at all levels would be considerable.

The Defence NBC Centre and the Wiltshire hazardous material working group have, after discussion and field trials, developed a simple, comprehensive, and cost-effective coordinated response to the management of chemical casualties. ${ }^{8}$ The management concept is an aggressive response at the incident site(s), with a multidisciplinary approach resulting in decontamination and resuscitation on site; a backup decontamination facility is placed outside each $A \& E$ department, with the equipment and procedures being identical to those used at the site. The levels of protection stipulated for the site are chemical suits, butyl rubber gloves, and breathing apparatus for any medical staff within the inner cordon; at the hospital, A\&E staff dealing with contaminated casualties require the same level of protection. If no direct contact will occur with contaminated clothing a double pair of surgical gloves may be used to undertake procedures, instead of the heavier butyl rubber gloves. It is recognised that national recommendations are being developed by the Ambulance Service Association chemical incident procedures subgroup.

MAJOR D MORGAN-JONES RAMC

Defence Nuclear, Biological and Chemical Centre, Winterbourne Gunner, Wiltshire

MAJOR T HODGETTS RAMC Military District Hospital Unit Frimley Park, Camberley, Surrey

1 Volans AP. Sarin: guidelines on the management of victims of a nerve gas attack. $f$ Accid Emerg Med 1996;13:202-6.

2 Clark KP, ed. Chemical and biological handbook. Royal Military College of Science, 1995.

3 Helm UK. Triage of chemical casualties. Bonn, 1991 (internal publication).

4 Cooper GJ, Ryan JM, Galbraith KA. The surgical management in war of penetrating surgical management in war of penetrating agents. $₹$ R Army Med Corps 1994;140:1 13-8.

5 Robertson AG, Morgan-Jones DJ. First line nuclear, biological and chemical medical defence training: the way ahead. $\mathcal{f} R$ Naval Med Service 1994;80:90-4.

6 Baxter PJ. Major chemical disasters: Britain's health services are poorly prepared. $B M F 1991$; 302:61-2.

7 Thanabalasingham T, Beckett MW, Murray V. Report of a chemical incident from ethyldichlorosilane. BMF 1991;302:101-2.

8 DNBCC and the Wiltshire Hazardous Material Working Group, 1995. Hazardous materials incidents: a guide to a co-ordinated response.

\section{The author replies:}

I am grateful that my article has been of interest to the experts in the military and beg forgiveness if the guidelines suggested are simplistic when compared with the highly trained response available within the Army.

It is not entirely clear that the factual inaccuracies mentioned do affect the likely response of the front line civilian services who would be called upon to respond in the event of a civilian attack.

I concentrated on sarin because (1) it relatively easy to produce with school level chemistry and (2) it has been used by terrorists and there is therefore a precedent. I hope the recipe for VX is not available on the Internet!

Sarin is volatile and consequently, as seen in Japan, most victims suffered vapour exposure with primarily ocular symptoms.
It would appear that the contents of the "Combopen" and the indications for the use of Fuller's earth have been altered since the publication of my source literature.

I was not advocating the enclosure of contaminated victims within casualty pouches, merely suggesting that this is a possible response from the fire and rescue service, presented with contaminated victims of an undiagnosed type in a stressful situation. It would be understandable for them to pass the problem up the line to the receiving hospital.

I agree that the response of civilian services to any major chemical contamination incident is likely to be haphazard in the extreme. These are rare events in the United Kingdom and an individual region may have never tested their plans.

That the Army has recently developed a chemical warfare ALS suggests that their responses to the chaos of such an event were deemed less than perfect.

I look forward with interest to the dissemination of the coordinated response advised by the Defence NCB Centre but wonder if in the reality of an attack on the underground or one of the many enclosed shopping complexes in the UK, this response will occur before contaminated victims arrive in an unprepared $A \& E$ department on a Friday afternoon during rush hour

The common perception of nerve gas injury involves a great amount of fear, with visions of NCB clad warriors dealing with lethally contaminated victims. My aim in writing the article was to show that the treatment of such victims is logical and beneficial and well within the abilities of any qualified doctor. I also wished to point out some of the practical difficulties and offer some suggestions as to their management and I am grateful to Major Morgan-Jones and Major Hodgetts for the additional information which has not so far not been generally available to the civilian practitioner.

A P VOLANS

Accident and Emergency Department, Royal Hallamshire Hospital, Glossop Road, Sheffield

\section{Deliberate self harm}

EDITOR,-Ryan et al ${ }^{1}$ present a valid case for the use of overnight observation wards in the management of deliberate self harm (DSH). From the data presented, the use of such wards reduces the need for psychiatric assessment of these patients.

My own experience of providing a $\mathrm{DSH}$ service which offers assessment to all patients who harm themselves would indicate that the provision of an observation ward improves the quality of psychiatric assessment and intervention. The contrast between working in casualty departments which do and do not admit DSH patients to an observation ward is often striking. Emergency assessments of DSH patients who are not deemed to warrant admission to a medical bed are frequently requested. In the absence of overnight observation beds, this often means attempting to address complex "multiple psychiatric and social problems" during the small hours of the morning, while the patient is still in crisis.

When DSH patients are admitted overnight, then a more meaningful assessment can be made the next morning, with full access to social and psychiatric support services. $\mathrm{Pa}$ tients will have had time to reflect upon recent events once they pass through a period of crisis. It is then possible to target appropriate interventions at those who will benefit most and patients can leave hospital with the appropriate follow up arrangements already in place.

There are in excess of 100000 annual DSH admissions in the United Kingdom, and some $15-20 \%$ of these patients will be readmitted within the following year. ${ }^{2}$ The provision of appropriate psychosocial intervention has the potential to both reduce the demands put upon $\mathrm{A} \& \mathrm{E}$ departments through readmission and to improve the quality of patient care offered. I believe that observation wards facilitate this process and would urge A\&E departments to consider their use in cases of DSH.

SIMON GILBODY

Academic Unit of Psychiatry, St fames University Hospital, Leeds

1 Ryan J. Clemmett S, Perez-Avila C. Managing patients with deliberate self harm admitted to an patients with deliberate self harm admitted to an Accid Emerg Med 1996;13:31-3.

2 House A, Owens D, Storer D. Psychosocial intervention after attempted suicide: is there a case for better services? Int Rev Psychiatry 1992;4: $15-22$.

\section{The authors reply:}

Thank you for offering us the opportunity to reply to Dr Gilbody's comments on our paper. We are encouraged that an academic unit of psychiatry supports the use of an A\&E observation ward in the management of deliberate self harm patients. Continued research in this area is important and we now keep a database of all patients who attend following an episode of DSH and are managed by the multidisciplinary team. Analysing these data base has stimulated us to look at other areas such as out patient detoxification, the association of DSH with drug dependency, and the management of frequent offenders, all of which can be appropriately managed by an experienced multidisciplinary team based in an $A \& E$ department.

We concur with Dr Gilbody's statement that an observation ward can improve the quality of patient care; however, further research is required in this area to assess the long term impact of such a practice. Those of us working in $A \& E$ medicine are in a unique position to be able to study this further and should not neglect our academic responsibilities.

JOHN RYAN SUE CLEMMETT CARLOS PEREZ-AVILA Accident and Emergency Department, Royal Sussex County Hospital, Eastern Rd, Brighton

Dogs, epilepsy and airways. The dog always wins!

EDIToR,-Injuries caused by dog bites are common and as many as 3 per 1000 population may attend accident and emergency $(\mathrm{A} \& \mathrm{E})$ departments in any one year. ${ }^{1}$ Epilepsy is also a common cause of attendance, with a prevalence in the population of $3 \%$. However, it is rare that both problems will occur in the same patient at the same time.

Patient 1 was a 20 year old male with unstable epilepsy who had owned a large, but friendly, German Shepherd for a number of years. Unfortunately on the first occasion that the dog witnessed his master having a seizure it became frightened and attacked the man's throat, causing a fracture of the thyroid and cricoid cartilages and puncturing the trachea. He presented to accident and emergency as a postictal airway obstruction requiring an emergency tracheostomy. 